\title{
18 Teachers and technology: the case of mathematical learning
}

\author{
Rosamund Sutherland \\ Graduate School of Education \\ University of Bristol, \\ England
}

\begin{abstract}
Mathematical microworlds provide a problem-space in which teacher and pupils can co-construct meaning so that the imbalance between the teacher's and pupils' knowledge is used productively to provoke pupils to leap into new mathematical ways of knowing. A sociocultural approach to learning implies that the mathematics teacher is critical whether software is more closed and directed or more open and exploratory. Furthermore, the teacher must become part of the sense-making system involved in joint problem solving, in which all partners are actively constructing meanings.
\end{abstract}

\section{Keywords}

Algebra, cognition, knowledge as a resource, teacher education.

\section{INTRODUCTION}

Computer availability in secondary schools has changed quite substantially over the last 15 years. Most schools in the UK are now relatively well equipped with computers and although lack of access is often given as a reason for non-use this is very rarely the case. The majority of teachers are still unclear about how to incorporate the computer into their teaching and have received very little training in this direction. This may be because the computer has tended to be viewed as an artefact which will somehow replace the teacher.

Within this paper I shall argue that the mathematics teacher is critical whether software is more closed and directive or more open and exploratory. This is because students are active constructors of knowledge whatever the teaching approach being used. Students strive to make sense of what is presented to them 
and construct their own meanings which will be appropriate in the local problem situation but may not be appropriate in a wider situation. So, for example, primary school pupils are likely to develop knowledge such as 'multiplication makes bigger' from interacting with positive whole number multiplication problems. This knowledge is adequate and functional for the problems being solved but will no longer be appropriate within a wider domain. For all learners the 'old' knowledge will interact with new knowledge when, for example, learning how to multiply decimal numbers. Many pupils then develop what are sometimes called misconceptions but which are merely conceptions which are no longer functional within the new situation. Within all this complexity the teacher has a crucial role in provoking pupils to discuss, explain, confront and develop.

\section{TWO VIEWS OF LEARNING AND KNOWLEDGE}

Computer environments for learning mathematics can be characterised as being somewhere along a continuum which ranges from the more open microworld-type environments to the more closed intelligent learning environments. Computerbased microworlds are designed with the expectation that students will learn through their own constructive thinking "transcending their cognitive limitations and engaging in cognitive operations they would not have been capable of otherwise" (Pea, 1985, p.171). These have been called cognitive tools or performance-oriented tools and within mathematics education include such software as Logo, spreadsheets and dynamic geometry environments. Intelligent learning environments incorporate sufficient artificial intelligence to make diagnostic, assessment and tutorial decisions for the student. Pea has called these environments pedagogic tools and they tend to be used to enhance the automatisation of particular mathematical skills which may respond to drill and practice.

Both types of environment have been accompanied by a desire to more or less remove the teacher from the learning environment (Balacheff and Sutherland, 1994). The reasons for this are two-fold, firstly there is a dominant view that teachers are the cause of many of students' problems with learning and secondly there is a drive to save money (this is particularly the case in the Higher Education and Further Education sectors). The very word teacher is out of fashion, being associated with over-authoritative modes of delivery. Research which has focused on misconceptions developed by pupils as a result of more traditional teaching and on the rich informal methods which pupils bring to solving mathematics problems (in the case of algebra see, for example, Booth, 1984) has influenced mathematics education policy to move towards a focus on individual learning. The individualised mathematics learning schemes which have proliferated in English primary and secondary schools are a tangible outcome of this emphasis on individual learning. Teachers are expected 'to start from what the pupil brings' and this quite laudable exhortation has led to a 
situation where such mathematical topics as algebra and proof can hardly be taught, because their very nature implies some sort of imposition of new knowledge by the teacher (for a discussion of this see Royal Society/JMC, 1997). Of course there are many other factors which have worked towards a de-emphasis of the role of the teacher and these include the relatively weak mathematical background of many primary school teachers and the difficulties in recruiting secondary mathematics teachers in the 80 s.

Ironically, whilst universities are rushing to embrace resource-based learning in computer form, the concerns about the mathematical background of our school leavers may have resulted from an over-emphasis on resource-based learning in paper form. This is because resource-based learning tends to result in less teacher involvement, although this does not have to be the case. Currently in England there are two forces which are emerging from the concern about the mathematics competence of school-leavers. The first of these is challenging the overly individualised approach to learning in schools and is calling for more whole class teaching, advocating what is being called a continental interactive style of teaching (for example the Gatsby Primary Mathematics Project). Observations of the mathematics classrooms in countries such as Switzerland, Hungary and Japan have revealed an approach to teaching in which the teacher works with the whole class with an expectation that all pupils move forward together. Individuals are often asked to present their ideas to the class and these are then discussed by the whole group. One of the main characteristics of this interactive approach is the ongoing dialogue between the teacher and pupils and also a collective sharing of knowledge.

The second emerging force is a push for intelligent learning environments such as Successmaker. Countries such as Mexico, England and Australia are viewed as being potential targets for a global market, which very often derives from the USA. The rhetoric surrounding intelligent learning environments is often an exaggerated version of individualised learning in which one-to-one tutoring is considered to be the most effective form of teaching. These systems appear to be gaining hold because of the current anxiety about standards in mathematics education. They may actually fulfil an important function but the heavy marketing by computer manufacturers, keen to sell both networked software and hardware, make them an unattractive implication of the globalisation of the market. Furthermore they may be supporting pupils to learn because they place emphasis on aspects of mathematics which text books and assessment schemes have tended to de-emphasise over the last 10 years. They involve a focus on the individual but with very little space for dialogue between teacher and pupil.

Of these two recent innovations the former derives from a more socially shared view of learning and the latter from an individualised view of learning with the computer taking on the role of the individual tutor. 


\section{THEORISING TEACHING AND LEARNING}

In my own research I have become increasingly influenced by what is called a sociocultural approach to learning. Central to this approach is the idea that mental functioning in an individual has its origins in social life. This position stresses the crucial role which communication through language and other semiotic systems plays in learning. Also crucial is the idea that human action is mediated by 'technical' and 'cognitive tools'. These tools are social in that they are the product of sociocultural history and are always used first as a means of influencing others and only later as a means of influencing oneself (Vygotsky, 1978).

Whatever the teaching approach used, students are active constructors of knowledge (Brousseau, 1997), that is they strive to make sense of the social and physical environment in which they are placed and they bring to a learning situation a history of previous experiences which also influences learning. Brousseau's theory has drawn attention to the fact that

"if learning stems from the interaction of the learner with his or her environment then the characteristics of that environment will make a difference to what is learned. The fundamental task of the teacher, to ensure that pupils engage in the problem to be solved with the appropriate mathematical meanings, depends on a negotiation which can be viewed as a transfer of responsibility from the teacher to the students. This is what Brousseau calls the 'devolution of the problem' . Interactions with students will initially be focused towards this end. If this devolution does not take place then students' making sense may involve trying to work out what it is the teacher is intending to teach, as opposed to engaging with the mathematical knowledge which is at stake" (Sutherland and Balacheff, 1997).

\section{BRIDGING THE GAP BETWEEN PUPILS' CONSTRUCTIONS AND SOCIAL KNOWLEDGE}

My research has always been concerned with designing learning situations which incorporate the use of computer-based microworlds such as Logo, spreadsheets or dynamic geometry environments (e.g., see Hoyles and Sutherland, 1989; Sutherland and Rojano, 1993). These environments offer enormous potential for students to engage with and learn mathematical ideas which they might otherwise find difficult. Mathematical expertise involves making connections within a system of mathematical ideas and developing an understanding of what Noss et al. (1997) have called the virtual reality of mathematics. Traditional teaching methods allowed pupils to view this virtual reality without supporting them in engaging with it. Pupil-centred approaches to learning deal with the engagement 
issue by situating mathematics within accessible and 'everyday' situations but rarely allow pupils access to the virtual reality of mathematics. Computermicroworlds allow both action and expression (or what Brousseau has called 'situations for action' and 'situations for formulation'). This is potentially an improvement on other forms of experiential learning because computer feedback supports successful mathematical action and associated expression. Interacting with computer-based microworlds inevitably involves interacting with a formal system which is not dissimilar to the formal mathematical system but which is not the same as the formal mathematical system. Symbolic screen-objects (for example spreadsheet cell or Cabri-drawing) are somewhere in between tangible mathematical objects (for example number or mechanism) and abstract mathematical objects (for example ' $x$ ' or geometrical figure). In this sense the phenomenology of the screen provides a middle-way into learning mathematics. (Sutherland and Balacheff, in press).

Sutherland and Balacheff (1997) set out the didactical complexity of computational environments for learning mathematics explaining why the teacher needs to understand what has been passing between student, computer and the computer-based activity. We emphasise the role of the teacher and discuss the ever-present risk that 'teaching' will divest pupils of the responsibility for their own learning.

When we consider the case of learning algebra, for example, there are two main reasons why the teacher has to play an important yet delicate role. The first is the language aspect of algebra, which cannot be learned through interactions with a problem alone. The second is that algebraic methods are qualitatively different from arithmetic methods and do not flow spontaneously from them. The situation is complex because the language of algebra is inextricably linked to the algebraic method. In our analysis of pupils learning algebra-related ideas with Logo and spreadsheets we have found that the teacher often has to intervene with suggestions which are at-odds with the pupil's current way of approaching the problem. This is because moving from an arithmetic to an algebraic approach requires a radical shift of attention. However our analysis of teacher/pupil interactions suggests that if we are successful with the devolution of the problem, then these interventions take place within a shared problem solving space in which the teacher is not likely to divest the pupil of the responsibility for solving the problem.

The Logo Maths project (Hoyles and Sutherland, 1989) was a three year longitudinal study of pupils learning Logo within their normal mathematics classroom (in this classroom pupils were working on an individualised learning scheme called SMILE). Pupils worked in pairs at the computer and the researchers acted as teachers who both observed the pupils' work (which was also video recorded) and intervened when it was judged to be appropriate. As teachers we wanted pupils to become independent learners who made decisions themselves, working on substantial and motivating Logo projects. This was the case with notions associated with variable. We waited for about a year for pupils 
to choose projects within which it would be natural to introduce the idea of variable and this hardly ever happened because pupils did not already have this theoretical idea available to them. For all the pupils who learned to confidently use the idea of variable there was always a period of relatively intensive dialogue in which the teacher and pupil(s) worked together. There is no doubt that within these interventions the teacher was imposing ideas which were at-odds with the pupils' ideas, but in the case of learning about variable in Logo there appeared to be no other way forward.

Within this project we used two forms of teacher intervention which were directed at teaching pupils the idea of variables. One was the design of activities to provoke the use of variable. The other was dialogue between teacher and pupils to 'push' them into using the idea of variable. One such designed activity was the 'Variable Letter Task' (Sutherland, 1993). For most of the pupils this task-based intervention was at-odds with their spontaneous approach and was reacted to by comments of the form "How can you do that if you don't know the number". Post hoc analysis suggests that what we were doing here was effectively saying "don't ask why until you have used the idea". Once pupils had experienced the power of using a variable we offered discussion and explanation. In fact it was virtually impossible to adequately answer 'why' questions when first introducing pupils to using variables. Explanation 'before doing' becomes rationalisation about an idea which is beyond experience, a rationalisation which can get in the way of experience.

Sally and Janet were one of the case study pairs we followed for three years. They were high attaining pupils within the normal mathematics class and were able to work independently and creatively. Looking back over every instance when the notion of variable was introduced to these pupils it is clear that the teacher intervention was always at-odds with the pupils' way of solving a problem. However, analysing Sally and Janet's development over a three year period indicates that relatively directive and intrusive interventions became incorporated into their way of working and were ultimately taken up spontaneously by them. Any analysis of isolated teacher interventions within this longitudinal negotiation of meaning between pupils and teacher could suggest that the teacher was insensitive to the pupils' problem solving approaches. For example when Sally and Janet were working on the design of a flower the following exchange took place:

Teacher Will you later think about how you can make that into a bigger flower ... using a variable input ...?

Sally We gotta think about making a flower first ... let alone making it bigger or smaller.

Despite this comment the pair did produce a general flower procedure by the end of the session. 
As discussed previously, if these interventions come when pupils are already engaged in solving a problem, they are not likely to take the responsibility for solving the problem away from the pupils. With less confident pupils there is more of a risk that teacher intervention will change the balance of responsibility. This is why we intervened less with the lower attaining pupils. However this resulted in these lower attaining pupils learning less about variable (Sutherland, 1993) and provides further evidence that it is teaching which provokes learning about variables in Logo. In a subsequent project in which low attaining pupils were expected to learn algebra-related ideas through work with spreadsheets we found that we had to firstly provoke the students to take responsibility for solving the spreadsheet problems for themselves and we did this by initially not answering their questions about how to solve a problem. Instead, we responded by encouraging them to work out strategies for themselves. When these less confident pupils had learned that we expected them to become engaged in the problems, we were then able to enter into joint problem solving in which we provoked them to use spreadsheet-algebra approaches as opposed to arithmetic approaches.

The type of intervention which is necessary to provoke a spreadsheet-algebra approach is illustrated by the exchange between the teacher and a 10-year-old student who was solving the following problem:

100 chocolates were distributed between three groups of children. The second group received four times as many chocolates as the first group. The third group received 10 chocolates more than the second group. How many chocolates did the first, the second and the third group receive (Sutherland and Rojano, 1993).

\section{Ernesto The point is that ... there is a difficulty there ... because ... \\ Teacher Why? \\ Ernesto Here, first of all you have to find out this value (he refers to the amount of chocolates in the first group, which is an unknown) and then multiply it by 10. \\ Teacher Although we don't know this value, we can suppose that it is 1, or that it is 2, or 3 and then build up a formula for the second group in any cell you choose.}

When faced with this type of problem many students spontaneously used an arithmetic approach in which they used the spreadsheet to calculate the total number of chocolates divided by the number of parts. We wanted the students to use a spreadsheet-algebra approach in which they use a spreadsheet cell to represent the unknown number of chocolates.

In the Logo Maths Project what pupils learned about variable was dependent on the extent to which the teacher intervened during a particular pair's work. In a subsequent project we worked with whole classes of pupils in a computer room. More of these pupils learned to confidently use variable than had been the case in 
the Logo project and within a shorter time period (Sutherland, 1993). This may have been partly because of a more refined set of activities designed to provoke the use of variable, but it may also be because whole class work can create a learning culture which can support more effective learning than is the case with individualised work. Within the computer room we were moving towards an interactive whole class approach and this was effective for learning Logo-maths and spreadsheet-maths. But we still did not adequately tackle the issue of teaching pupils to make links between the computer-based world and other mathematical worlds. We expected pupils to make these links spontaneously. Some pupils did, but not the majority.

What had been missing from much of the above computer-based work was an interactive and collective institutionalisation phase of learning, in which the teacher draws on the pupils' computer-based work and emphasises the links to socially accepted mathematical knowledge. This institutionalisation phase has always been an important part of lessons which I have observed in France when Cabri-géomètre is being used to teach geometry and trigonometry (e.g., see Capponi and Sutherland, 1992). Essential elements of this work usually consist of 'situations for action' (computer work with Cabri), 'situations for formulation' (computer work and discussion in groups of the Cabri work) and 'situation for institutionalisation' (presentation of the groups' work orchestrated by the teacher to draw out and emphasise relevant mathematical ideas). This way of working is similar to the whole class interactive teaching discussed earlier.

\section{CONCLUDING REMARKS}

A sociocultural approach to learning places an emphasis on students' individual and group actions with cognitive tools. These tools range from mathematical sign systems to computer-based mediational means. Pupils have to learn to use these culturally constructed tools in order to enter the virtual world of mathematics. Computer-based microworlds offer a powerful way into the virtual world of mathematics but it is the teacher who has to provide the support for pupils if they are to leap into this world.

The teacher becomes part of the sense-making system involved in joint problem solving, in which all partners are actively constructing meanings. In the case of the teacher this active construction will involve thinking about how pupils learn, thinking about pupils' informal knowledge, thinking about mathematics and thinking about the computer-based microworld. In order to do this the teacher enters into a dialogue with pupils which is based on communication in natural language and other mathematical and computer-based sign systems. The computer is a new technological tool which can support the teacher in working together with pupils, engaging in dialogue about what the pupils know in order to communicate the possibilities of new knowledge. Intelligent learning environments provide the teacher with information about assessment scores and 
levels of attainment but are not designed to provoke joint problem solving. Microworlds can be used to provide a joint problem-space in which teacher and pupils co-construct meaning and in which the imbalance between the teacher's and pupils' knowledge is used productively to provoke the pupils 'to leap' into new mathematical ways of knowing.

The dialogue between teacher and pupil is an essential element of this productive knowledge construction. Dialogue is central to the one-one Télé-Cabri scenario described by Balacheff in this volume (see Chapter 14), in which the teacher interacts at a distance with the pupil. But if the social dynamic of interactive whole class work (with pupils present or possibly at a distance) is also an important element of effective and efficient learning then this will have to be planned for in our visions of learning at a distance with electronic technologies.

\section{REFERENCES}

Balacheff, N and Sutherland, R (1994). Epistemological Domain of Validity of Microworlds: The Case of Logo and Cabri-géomètre. In R. Lewis and P. Mendelsohn (eds.) Lessons from Learning, IFIP TC3/WG3.3 Conference, North Holland, 137-150.

Booth, L. (1984). Algebra: Childrens' strategies and errors. Windsor, UK: NFER-Nelson.

Brousseau, G. (1997). Theory of Didactical Situations in Mathematics. Dordrecht: Kluwer Academic Press.

Capponi, B and Sutherland, R. (1992). Trigonometry with Cabri in a French Classroom, Micromath, 8, 32-33.

Hoyles. C. and Sutherland, R. (1989). Logo Mathematics in the Classroom. London, UK: Routledge.

Noss, R., Healy, L. and Hoyles, C. (1997). The Construction of Mathematical Meaning,: Connecting the Visual with the Symbolic. Educational Studies in Mathematics, 33(2), 203-233.

Pea, R. (1985). Beyond Amplification: Using the computer to reorganize mental functioning. Educational Psychologist, 20, 167-182.

Royal Society/JMC (Joint Mathematical Council) Working Group (1997). Teaching and Learning Algebra Pre-19. London, UK: Royal Society.

Sutherland, R. (1993). Connecting Theory and Practice: Results from the Teaching of Logo, Educational Studies in Mathematics, 24, 1-19.

Sutherland, R and Balacheff, N. (1997). Didactical Complexity of Computational Environments for the Learning of Mathematics. Research Report, Graduate School of Education. University of Bristol, UK.

Sutherland, R. and Rojano, T. (1993). A Spreadsheet Approach to Solving Algebra Problems. Journal of Mathematical Behaviour, 12(4), 351-383. 
160 Information and communications technologies in school mathematics

Vygotsky, L ( 1978). Mind in Society: The Development of Higher Psychological Processes. Cambridge, Mass.: HUP.

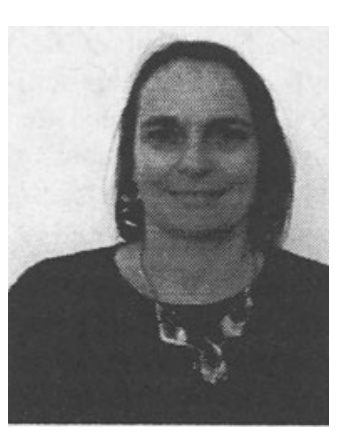

Rosamund Sutherland is professor of education at the University of Bristol. Her research is concerned with modelling the interrelated process of teaching and learning, with a particular focus on mathematics and science. A graduate in mathematics, her post-graduate research was on the use of Logo for learning algebra. The computer as a cognitive tool is a central theme in her work with new technologies. She currently chairs the Centre for Learning, Knowing and Interactive Technologies (LKIT) which places an emphasis on what an individual can learn when mediated by a wide range of social, technological and epistemological resources. 